method has the potential to revolutionize the field of cardiothoracic surgery. Most of all, the continued joint efforts of developmental biologists and material scientists and engineers in the area of cell printing may lead to faster tissue construction, a cornerstone to making regenerative medicine a clinical possibility.

\section{References}

1. Sun W, Lal P. Recent development on computer aided tissue engineering-a review. Comput Methods Programs Biomed. 2002;67:85103.

2. Langer R, Vacanti JP. Tissue engineering. Science. 1993;260:920-6.

3. Hutmacher DW. Scaffolds in tissue engineering bone and cartilage. Biomaterials. 2000;21:2529-43.

4. Yang S, Leong KF, Du Z, Chua CK. The design of scaffolds for use in tissue engineering. Part II. Rapid prototyping techniques. Tissue Eng. 2002;8:1-11.
5. Vozzi G, Flaim C, Ahluwalia A, Bhatia S. Fabrication of PLGA scaffolds using soft lithography and microsyringe deposition. Biomaterials. 2003;24:2533-40.

6. Landers R, Hubner U, Schmelzeisen R, Mulhaupt R. Rapid prototyping of scaffolds derived from thermoreversible hydrogels and tailored for applications in tissue engineering. Biomaterials. 2002;23:4437-47.

7. Sachlos E, Czernuszka JT. Making tissue engineering scaffolds work. Review: the application of solid freeform fabrication technology to the production of tissue engineering scaffolds. Eur Cell Mater. 2003;5: 29-39.

8. Sachlos E, Reis N, Ainsley C, Derby B, Czernuszka JT. Novel collagen scaffolds with predefined internal morphology made by solid freeform fabrication. Biomaterials. 2003;24:1487-97.

9. Wilson WC Jr, Boland T. Cell and organ printing 1: protein and cell printers. Anat Rec. 2003;272A:491-6.

10. Mironov V, Boland T, Trusk T, Forgacs G, Markwald RR. Organ printing: computer-aided jet-based 3D tissue engineering. Trends Biotechnol. 2003;21:157-61.

11. Boland T, Mironov V, Gutowska A, Roth EA, Markwald RR. Cell and organ printing 2: fusion of cell aggregates in three-dimensional gels. Anat Rec. 2003;272A:497-502.

\title{
Selective reduction of the septolateral dimensions in functional mitral regurgitation by modified-shape ring annuloplasty
}

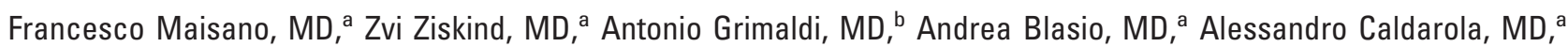 \\ Michele De Bonis, MD, ${ }^{a}$ Giovanni La Canna, MD, and Ottavio Alfieri, MD, ${ }^{\text {a }}$ Milan, Italy
}

$\mathrm{U}$ ndersized annuloplasty is the conventional surgical treatment for functional mitral regurgitation (FMR). ${ }^{1}$ The rationale of this approach is the reduction the annular diameter to force leaflet coaptation. When this technique is performed with a conventional annuloplasty prosthesis, the transverse and septolateral dimensions are proportionally reduced. However, it has been suggested that the main determinant of malcoaptation in FMR is the increase of the septolateral dimension. ${ }^{2}$ Therefore, intercommissural distance reduction is probably unnecessary, if not detrimental (it may induce anterior leaflet folding and unnecessary reduction of the total mitral valve orifice area).

We herein present an alternative method for annuloplasty, designed to selectively reduce the septolateral dimension in FMR,

\footnotetext{
From the Departments of Cardiac Surgery a and Non-invasive Diagnostic Cardiology, ${ }^{\text {b }}$ San Raffaele Foundation Institute and University Hospital, Milan, Italy.

Received for publication May 20, 2004; accepted for publication June 1, 2004.

Address for reprints: Francesco Maisano, MD, Cardiochirurgia, Istituto Scientifico Universitario, San Raffaele, Via Olgettina 60, 20132 Milano, Italy (E-mail: Francesco.maisono@hsr.it).

J Thorac Cardiovasc Surg 2005;129:472-4

$0022-5223 / \$ 30.00$

Copyright $\odot 2005$ by The American Association for Thoracic Surgery

doi:10.1016/j.jtcvs.2004.06.051
}

which is intended to improve the results of mitral repair in this challenging group of patients. ${ }^{3}$

\section{Surgical Technique and Clinical Experience}

A Carpentier rigid ring (Edwards Lifesciences Inc, Irvine, Calif) was chosen because it contains a metal core that can be reshaped. Prosthesis size was selected by measuring the intertrigonal distance and was undersized by 1 size. Before implantation, the ring was reshaped according to the sequence illustrated in Figure 1 by use of 2 tubing clamps. Shape modification created a prosthesis with the intertrigonal distance upsized by 1 size (and therefore normalized to the native valve intertrigonal dimension) and the septolateral distance undersized by 1 size (therefore, the septolateral dimension was doubly undersized), resulting in a nearly $2: 1$ intercommissural-septolateral ratio (as compared with the standard $4: 3$ ratio).

We used this approach in 14 patients with FMR between March and December 2003. There were 12 men and 2 women, with a mean age of $56 \pm 11$ years. Ten patients had ischemic and 4 had idiopathic cardiomyopathy. Preoperative mean functional class was $2.6 \pm 0.6$. FMR was severe in 12 patients and moderate in 2 (the mean regurgitation grade was $3.8 \pm 0.6$ ). The mean coaptation depth was $1.09 \pm 0.44 \mathrm{~cm}$ (range, $0.6-2.0 \mathrm{~cm}$ ) and exceeded $1 \mathrm{~cm}$ in 6 patients. ${ }^{4} \mathrm{~A}$ complex regurgitant jet (eccentric or multiple) was detected in 9 patients. ${ }^{5}$ The mean tenting area was $2.1 \pm 0.82$ $\mathrm{cm}^{2}$ (range, $1.3-4 \mathrm{~cm}^{2}$ ). The mean size of the implanted Carpentier ring was $29.7 \pm 2.6$. Associated procedures included the edge-toedge procedure (12 patients), coronary revascularization (10 pa- 

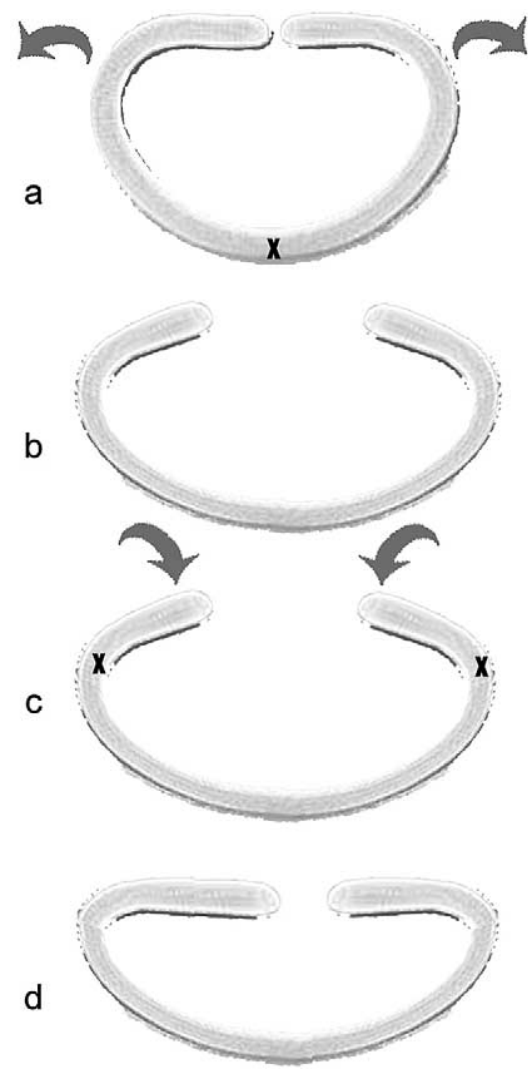

Figure 1. a, The original Carpentier Classic ring is shown. The prosthesis is first bent laterally by applying force on the points depicted by the $x$ and by having the middle of the posterior portion of the prosthesis as the hinge. $b$, The initial result is a prosthesis with a wider intercommissural dimension. c, A second step is needed to restore the $D$ shape of the prosthesis by bending the prosthesis at the level of the commissures $(x)$. $d$, The final result is a prosthesis with a normalized intercommissural distance, a doubly undersized septolateral dimension, and a wider gap in the anterior portion of the annuloplasty device (a suture is passed across the gap to avoid future distension).

tients), and left ventricular remodeling (4 patients). There were no hospital deaths or complications related to the modified-shape prosthesis implantation. On predischarge echocardiography, the mean mitral regurgitation (MR) grade was $0.5 \pm 0.65$ (decreased from a preoperative value of $3.8 \pm 0.6 ; P<.001), 13$ patients had no or trace MR, and 1 had mild $(2+)$ residual MR. The planimetric mitral valve area was $2.8 \pm 0.49 \mathrm{~cm}^{2}$. No significant gradient across the mitral valve was detected. During follow-up $(5 \pm 2.5$ months; range, 1-11 months), there have been no deaths or rehospitalizations. The mean New York Heart Association functional class decreased from the preoperative value of $2.6 \pm 0.6$ to $1.1 \pm$ $0.3(P<.0001 ; 12$ patients were in class I and 2 in class II $)$. Nonsignificant progress in mean MR severity was observed during follow-up (from $0.5 \pm 0.65 \mathrm{~cm}^{2}$ to $0.78 \pm 0.67 \mathrm{~cm}^{2}, P=.4$ ). On 3-dimensional echocardiography, the annuloplasty prosthesis retained the modified shape with the $2: 1$ ratio between the intercommissural and the septolateral dimensions (Figure 2).

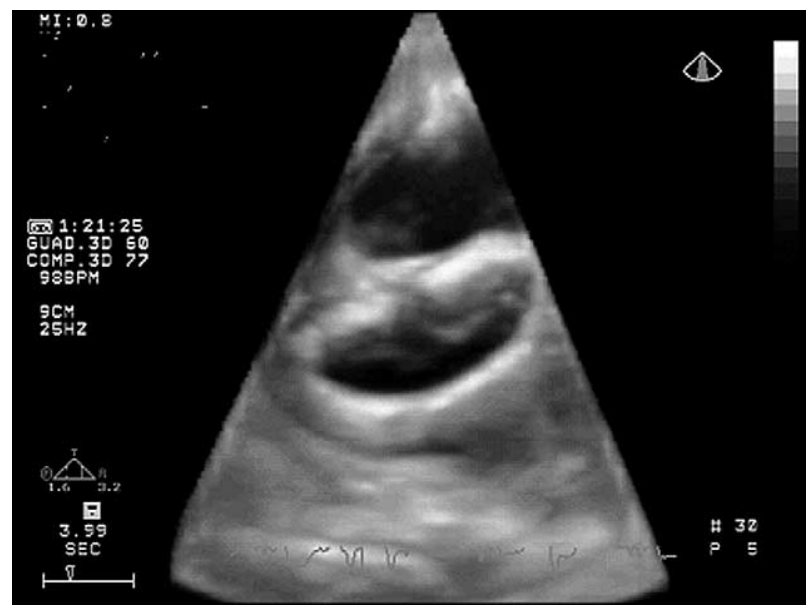

Figure 2. A follow-up 3-dimensional echocardiographic picture showing the typical D shape of the annuloplasty prosthesis, with a decreased septolateral dimension and with an approximately 2:1 ratio of the intercommissural-septolateral dimensions.

\section{Discussion}

Undersized annuloplasty, introduced by Bolling and associates, ${ }^{1}$ is extensively used to treat FMR. The rationale is to force leaflet coaptation by reducing annular dimensions. The ideal undersized annuloplasty should primarily address the septolateral diameter without affecting the transverse diameter so as not to distort the anterior annulus, which is not dilated among these patients and provides adequate mitral valve area. The available ring prostheses were originally designed to correct degenerative or rheumatic disease and to reduce both the transverse and the septolateral diameters proportionally in the 4:3 ratio. Implanting a size 28 ring in a size 32 mitral valve reduces the intercommissural diameter by $12 \%$ and the septolateral diameter by only $25 \%$, whereas when the shape of a Carpentier ring is modified, as has been documented by 3-dimensional echocardiography, the intercommissural length is not affected, and the septolateral diameter is reduced up to $50 \%$. The satisfactory mitral valve area of $2.8 \pm 0.49 \mathrm{~cm}^{2}$ found in our patients can be explained by a single dimension reduction.

We conclude that shape modification of a ring annuloplasty is an effective adjunct for valve repair in FMR. It provides effective apposition of the mitral leaflets without compromising transmitral flow and the shape of the anterior leaflet. The good immediate and early results encourage the extension of the indications for annuloplasty to subgroups with a high risk for recurrence, such as patients with a coaptation depth more than $1 \mathrm{~cm}$ and those with complex regurgitant jets. Dedicated prospective comparative studies with longer follow-up are needed to clarify the possible advantages of this technique over conventional undersized annuloplasty.

\section{References}

1. Bolling SF, Deeb GM, Brunsting LA, et al. Early outcome of mitral valve reconstruction in patients with end-stage cardiomyopathy. $J$ Thorac Cardiovasc Surg. 1995;109:676-82. 
2. Tibayan FA, Rodriguez F, Langer F, et al. Annular remodeling in chronic ischemic mitral regurgitation: ring selection implications. Ann Thorac Surg. 2003;76:1549-54.

3. Tahta SA, Oury JH, Maxwell JM, et al. Outcome after mitral valve repair for functional ischemic mitral regurgitation. J Heart Valve Dis. 2002;11:11-8.
4. Calafiore AM, Gallina S, Di Mauro M, et al. Mitral valve procedure in dilated cardiomyopathy: repair or replacement? Ann Thorac Surg. 2001; 71:1146-52.

5. Gillinov AM, Wierup PN, Blackstone EH, et al. Is repair preferable to replacement for ischemic mitral regurgitation? J Thorac Cardiovasc Surg. 2001;122:1125-41. 